\title{
EFFECT OF GONADOTROPIN AND ESTROGEN ON CHANGES IN LEVELS OF PROSTAGLANDIN IN RAT OVARY
}

\author{
Norihisa INAZU, Hiroshi KOGO and Yoshio AIZAWA \\ Department of Pharmacology. Tokyo College of Pharmacy. \\ 1432-1 Horinouchi, Hachioji, Tokyo 192-03, Japan
}

Accepted November 5, 1980

\begin{abstract}
Effects of gonadotropin and estrogen on the levels of prostaglandin (PG) in the rat ovary were investigated. PGF content in rat ovary. as measured by radioimmunoassay, was slightly higher than that by bioassay using rat stomach fundus, although there was no statistically significant difference. PGE and PGF levels in rat ovary during the estrous cycle were lowest on the day of diestrus. PGE was of the highest level on the day of estrus, and PGF on the day of proestrus. Both PGE and PGF were increased 24 hours after treatment with pregnant mare serum gonadotropin on the first day of diestrus. PGE was increased about 2.5 fold and PGF about 2.3 fold. PGF was significantly increased 24 hours after treament with estradiol on the first day of diestrus. These results suggest that gonadotropin may directly or indirectly regulate changes in ovarian $P G$ content via actions of estrogen.
\end{abstract}

There are reports on the action of prostaglandins (PGs) on reproductive function. Aspirin and indomethacin, inhibitors of $P G$ biosynthesis, inhibits ovulation in rats $(1-3)$. and levels of PGE and PGF in ovarian follicles were markedly increased immediately before ovulation in rats (4-6) and rabbits (7). it has been reported that luteinizing hormone (LH) and follicle stimulating hormone (FSH) in vitro have a stimulating action on $P G$ biosynthesis in Graafian follicles before ovulation (8, 9). Blatchley and Donovan demonstrated that exogenous $P G F_{2 \alpha}$ had a significant luteolytic effect in guinea-pigs (10), and that PGF in the utero-ovarian vein of the guinea-pig treated with estrogen could not be detected in the case of hy-

This study was presented in preliminary form at the 50th General Meeting of the Japanese Pharmacological Society, Tokyo. March, 1977. sterectomy (11). On the basis of these results, they suggested that the luteolysin derived from the uterus was $P G F_{2 a s}$. PGF $2 a s$ derived from the uterus brings about luteolysis in many different species $(12,13)$. More recently, it has been reported that progesterone and 20x-hydroxy-4-en-3-one in rat ovary were steeply decreased within 10 min after injection of $\mathrm{PGF}_{2 \alpha}$ into the uterine lumen and that estradiol was gradually increased (14).

We investigated the effects of gonadotropin and estrogen on PG content in rat ovary in an attempt to elucidate the role of $P G$ in rat ovarian function.

\section{MATERIALS AND METHODS}

Female Wistar rats weighing about $200 \mathrm{~g}$ were housed five per cage under controlled conditions of light and temperature. Vaginal 
smears were examined every morning, and rats exhibiting a regular 4-day estrous cycle were used for the experiments. At each stage in the estrous cycle, rats were sacrificed for the determination of $P G$ content in the ovary. Pregnant mare serum gonadotropin (PMS. Teikoku Zoki Pharmaceutical Co.) and human chorionic gonadotropin (HCG, ibid) were dissolved in $0.9 \%$ saline and were given 5.c. on the first day of diestrus (50 IU and $25 \mathrm{IU}$ per rat, respectively). Estradiol was dissolved in sesame oil and $20 \% \mathrm{~g}$ of estradiol was given s.c. to each rat on the first day of diestrus. Ovaries were removed 24 hours after treatment with each hormone and were weighed. After homogenizing the ovary in acidified alcohol, the $P G$ in the ovary was extracted with ethyl ether (15). The whole fraction was separated into PGE and PGF by silica-gel column chromatography (16) and each fraction was measured by bioassay using rat stomach fundus (17). PGF in the rat ovary was measured by a radioimmunoassay kit (Clinical Assays, Inc.) for comparison with the results of the bioassay.

\section{RESULTS}

Measurement of PGF content in rat ovary by bioassay and radioimmunoassay: PGF content in rat ovary on the day of diestrus was measured by bioassay using rat stomach fundus and by radioimmunoassay (Table 1).
Although PGF content $(1.05 \pm 0.157 \mathrm{ng} /$ ovary) measured by radioimmunoassay was slightly higher than that $0.65 \pm 0.056 \mathrm{ng} /$ ovary) by bioassay, the difference was not significant. In the subsequent experiments, PG content in rat ovary is shown as the level which was measured by bioassay.

$P G$ content in rat ovary during the estrous cycle: $P G E$ and $P G F$ in rat ovary were measured at different phases of the estrous cycle. The level of PGE was lowest on the day of diestrus and highest on the day of estrus, about 2.7 fold as compared with that on the day of diestrus (Fig. 1). The level of PGF was lowest on the day of diestrus as well as PGE content, and highest on the day of proestrus, about 9.1 fold as compared with that on the day of diestrus, but there was a

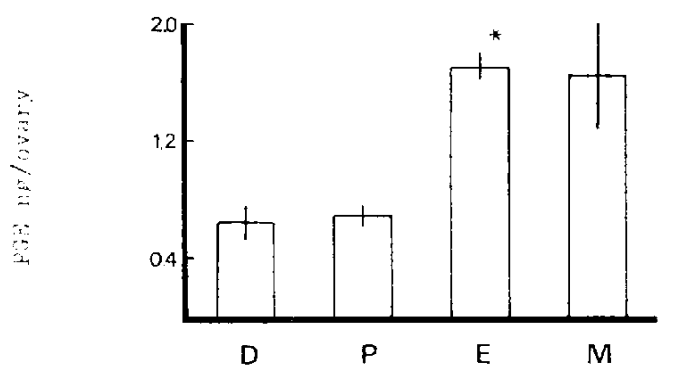

Fig. 1. Prostaglandin $E$ content in rat ovary during the estrous cycle. PGE was measured by bioassay using rat stomach fundus. Each column shows the mean of $4-6$ rats and vertical bar indicates standard error of the mean. D: Diestrus. P: Proestrus, E: Estrus, $\mathrm{M}$ : Metestrus. * $p<0.01$ : Significantly different from diestrus.

Table 1. Prostaglancin F content in rat ovary by bioassay and radioimmunoassay

\begin{tabular}{ccc} 
No. of rat & Bioassay & Radioimmunoassay \\
1 & 0.6 & -69 \\
2 & 0.54 & 1.45 \\
3 & 0.66 & 0.99 \\
4 & 0.8 & 1.08 \\
Mean+SE & $0.65 \pm 0.056$ & $1.05 \pm 0.157$ \\
\hline
\end{tabular}

(ng/ovary)

One rat ovary was used for bioassay and the other for radioimmunoassay. 
Table 2. Effect of PMS and $\mathrm{HCG}$ on prostaglandin content in rat ovary

\begin{tabular}{|c|c|c|c|c|c|c|}
\hline Group & \multicolumn{5}{|c|}{ Prostaglandin Content } & Mean $\pm S E$ \\
\hline \multirow{2}{*}{ Contral } & PGE & 0.8 & 0.4 & 0.6 & 0.4 & $0.6 \pm 0.10$ \\
\hline & PGF & 0.4 & 0.2 & 0.6 & 1.2 & $0.6 \pm 0.22$ \\
\hline \multirow{2}{*}{ PMS } & PGE & 0.6 & 2.0 & 0.8 & 2.4 & $1.5 \pm 0.44$ \\
\hline & PGF & 1.4 & 1.6 & 1.0 & 1.4 & $1.4 \pm 0.13^{* *}$ \\
\hline \multirow{2}{*}{$\mathrm{HCG}$} & PGE & 0.3 & 0.6 & 0.5 & 0.5 & $0.5 \pm 0.06$ \\
\hline & PGF & 0.2 & 0.5 & 0.2 & 0.4 & $0.3 \pm 0.08$ \\
\hline
\end{tabular}

All values are expressed as ng per ovary. PMS (50 IU) and HCG (25 IU) were dissolved in $0.9 \%$ saline and given S.C. on the first day of diestrus. Rats were sacrificed 24 hours after each hormonal injection. *p 0.05: Significantly different from control. PMS: prognant mare sorum gonadotropir. HCG: human chorionic gonadotropin.

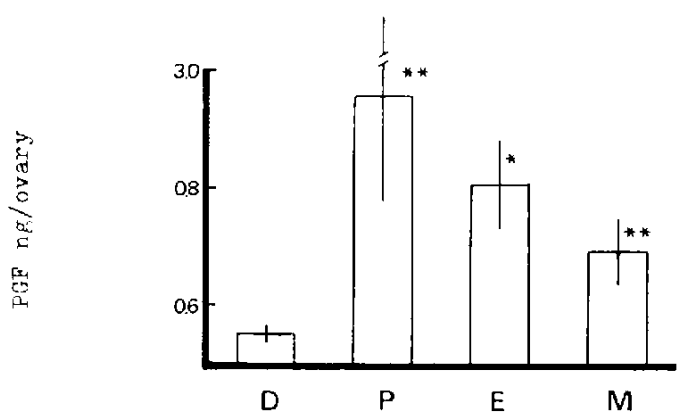

Fig. 2. Prostaglandin $F$ content in rat ovary during the estrous cycle. PGF was measured by bioassay using rat stomach fundus. D: Dicstrus. P: Proestrus, E: Estrus, M: Metestrus. ${ }^{*}$ P 00.05 . *p<0.01: Significantly different from diestrus.

considerable variation. PGF content was also about 6.6 fold higher on the day of estrus than on the day of diestrus (Fig. 2).

Effect of gonadotropin on PG content in rat ovary: Effects of PMS and HCG on PG content in rat ovary were also studied (Table 2). Although the treatment of PMS increased both PGE and PGF levels to about 2.5 fold and 2.3 fold, respectively, of the control levels, only PGF content was more significantly increased $(p<0.05)$. The treatment of $H C G$ tended to decrease both PGE and PGF contents in rat ovary, but there was no significant difference.

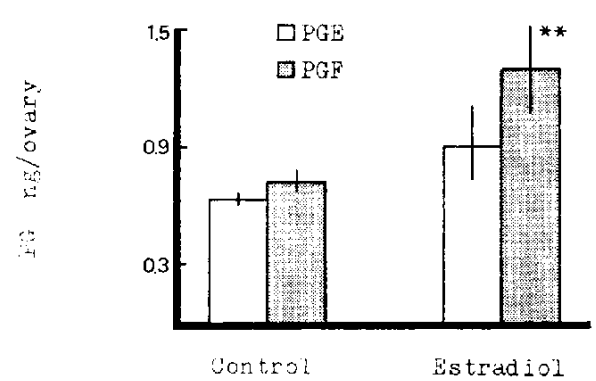

Fig. 3. Effect of estradiol on prostaglandin content in rat ovary. Estradiol $(20 \mu \mathrm{g})$ was dissolved in sesame oil and given s.c. on the first day of diestrus. Rats were sacrificed 24 hours after estradiol injection. ${ }^{*} p<0.05$ : significantly different from control.

Effect of estradiol on $P G$ content in rat ovary: Effect of estradiol on $P G$ content in rat ovary was then studied (Fig. 3). PGF content was $1.3 \pm 0.23 \mathrm{ng} /$ ovary after estradiol injection and increased about 1.8 fold as compared with that of the control $(0.7 \pm 0.05$ $n g$ /ovary, $p<0.05$ ). There was no significant change in PGE content after the estradiol injection.

\section{DISCUSSION}

Two methods, bioassay and radioimmunoassay, were used for the measurement of $P G F$ content in rat ovary. No significant 
difference between PGF levels measured by the two methods was recognized (Table 1). although the PGF level measured by radioimmunoassay was slightly higher than that by bioassay. Lipids other than PG may also participate in the measurement of PGF content by radioimmunoassay (18), therefore $P G$ content in the subsequent experiments (Figs. 1-3 and Table 2) was determined by bioassay with smooth muscle (17).

PG content in the ovary fluctuated at different phases of the estrous cycle indicating that the $P G$ content is closely related to the secretion of the sex hormones. In particular. the large variation of PGF content on the day of proestrus may reflect the fact that follicular $P G$ is rapidly increased immediately before the ovulation (4-6). These are interesting results in view of the fact that gonadotropin and ovarian steroids are secreted in large amounts on the day of proestrus in rat. Although it has been confirmed that $P G$ stimulates ovulation (19), the acting site and the mechanisms involved are poorly understood. Clark et al. (8) and Bauminger et al. (9) showed that the formation of $P G$ in rat Graafian follicles was stimulated by $\mathrm{LH}$ or FSH. In the present study, PMS and HCG which have a stimulatory action on follicular maturation and ovarian steroidogenesis were used to investigate whether or not the ovarian PG content is modified by gonadotropin. Both PGE and PGF contents in diestrous rat ovary were increased by PMS treatment but tended to decrease with $\mathrm{HCG}$ treatment. We suggest that the sensitivity of ovary to gonadotropin for $P G$ production differs between diestrus and proestrus. In contrast, it has been reported that the effect of PG on steroid contents in hypophysectomized rat ovary differs from that in the intact rat ovary (14). When estradiol was given to the rat on the first day of diestrus, the content of ovarian PGF increased (Fig. 3) as compared to the PMS treated rat.
However, the change in the PGE after the $P M S$ administration increased with somewhat fluctuation, therefore, the significance may not be statistical. On the other hand, it has been observed that PGF content in rat uterus was increased on the day of proestrus when estrogen levels reached a maximum (20) and that PGF content in the uterus of ovariectomized rat increased with estrogen treatment (21). Moreover there was an increase in PGF level in the utero-ovarian vein after estrogen administration to guinea-pigs (11) and rats (22). Thus, the $P G$ derived from the uterus may also have some influence on the $P G$ content in the rat ovary. though it has been confirmed in many species (except humans) that $P G F_{x}$ derived from uterus causes a luteolysis (23).

Our results suggest that $P G$ content in the rat ovary may be regulated not only directly by gonadotropin, as reported in the case of the rat (8, 9) and rabbit (24), but also indirectly via estrogen.

\section{REFERENCES}

1) Orczyc, G.P. and Behrman, H.R.: Ovulation blockace by aspirin or indomethacin: in vivo evidence for a role of prostaglandin in gonadotropir secretion. Prostaglandins 1, 3-21 (1972)

2) Armstrong, D.T. and Grinwich, D.L.: Blockade of spontaneous and LH-induced ovulation in rats by indomethacin, an inhbitor of prostaglandin biosyntesesis. Prostaglandins 1, 21 28(1972)

3) Tsafrifri, A., Linder, H.R., Zor, U. and Lamprecht, S.A.: Physiological rolo of prostaglandins in the induction of ovulation. Prostaglandins 2, 1-10 (1972)

4) LeMaire, W.J., Leidner, R. and Marsh, J.M.: Pre and post ovulatory charges in the concentration of prostaglandin in rat Graafian follicles. Prostaglandins 9, 221-229 (1975)

5) Bauminger, S. and Linder, H.R.: Preovulatory changes in ovarian prostaglandin formation and their hormonal control in the rat. Prostaglandins 9,737-751 (1975)

6) Iesaka, T., Sato, T. and Igarashi, M.: Role of crostaglandin $F_{: x}$ in ovulation. Endocr. japon. $22,279-285(1975)$

7) LeMaire, W.J., Yang, N.S.T., Behrman, H.R. 
and Marsh, J.M.: Preovulatory changes in the concentration of prostaglandin in rabbil Graafian follicles. Prostaglandins 3, 367-375 (1973)

8) Clark, M.R., Marsh, J.M. and LeMaire, W.J.: The role of protein synthesis in the stimulation by $\mathrm{LH}$ of prostaglandin accumulation in rat preovulatory follicles in vitro. Prostaglandins 12 . 209-216 (1976)

9) Bauminger, S., Lieberman, M.E. and Linder, H.R.: Steroid-independent offoct of gonadotropin on prostaglandin synthesis in rat Graafian follicles in vitro. Prostaglandins 9, 753-763 (1975)

10) Blatchley, F.R. and Donovan, B.T.: Luteolytic effect of prostaglandin in the guinea-pig. Nature 221, 1065-1066 (1966)

11) Blatchley, F.R., Donovan, B.T., Poyser, N.L., Horton, D.W., Thompson, C.J. and Los, M. Identification of prostaglandin $F_{2 n}$ in the uteroovarian blood of guinea pig after treatment with oestrogen. Nature 230, 243-244 (1971)

12) Flint, A.P.F. and Hillier, K.: Prostaglandins and reproduction. Edited by Karim, S.M.M., p. 271308. MTP Press, Lancaster (1975)

13) Zor, U. and Lamprecht, S.A.: Biochemical action of hormones. Edited by Litwack. G., Vol. 4, p. 85-133. Academic Press. New York (1977)

14) Takahashi, M. and Aizawa, Y.: Effect of uterine prostaglandin $F_{2 x}$ on the level of ovarian steroids in rats. Folia pharmacol. iapon. 76. 93-97 (1980) (Abs. in English)

15) Takeuchi, K., Yamada, $K$ and Aizawa, $Y$.: Biological assay of prostaglandin using rat uterus. Folia pharmacol. japon. 71, 675-682 (1975) (Abs. in English)

16) Arai, Y., Takeuchi, K., Yamada, K., Kogo, H. and Aizawa, Y.: Influence of carragenin inflammation on prostaglandin release from rat synovial membrane and action of anti-inflammatory drugs. Folia pharmacol. japon. 75, 765-769 (1979) (Abs. in English)

17) Takeuchi, K., Kogo, H. and Aizawa, Y.: Biological assay of prostaglandin in rat urine using fundus of rat stomach. Folia pharmacol. japon. 76, 179-184 (1980) (Abs. in English)

18) Hirata, H.: Metabolism and disease, Edited by

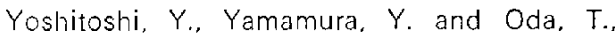
Vol. 12, p. 53-60, Nakayama Press (1975)

19) Armstrong, D.T., Grinwich, D.L., Moon, Y.S. and Zamecnic, J.: Inhibition of ovulation in rabbits by intrafollicular injection of indomethacin and prostaglandin F antiserum. Life Sci. 14, 129-140 (1974)

20) Ham, E.A., Cirillo, V.J.r Zanetti, M.E. and Kuehl, F.A.: Estrogen- induced synthesis of specific prostaglandins in the uterus. Proc. natn. Acad. Sci. U.S.A. 72, 1420-1424 (1975)

21) Kogo, H., Yamada, K. and Aizawa, Y.: Effect of estradiol on prostaglandin metabolism in rat uterus. Prostaglandins 13, 785-794 (1977)

22) Castracane, V.D. and Jordan, V.C.: Consideration into the mechanism of estrogenstimulated uterine prostaglandin synthesis. Prostaglandins 12, 243-251 (1976)

23) Behrman, H.R.: Prostaglandins in hypothalamopituitary and ovarian function. A. Rev. Physiol. 41, 685-700 (1979)

24) Marsh, J.M., Yang, N.S.T. and LeMaire, W.J.: Prostaglandin synthesis in rabbit Graafian follicles in vitro. Effect of luteinizing hormone and cyclic AMP. Prostaglandins 7, 269-283 (1974) 